\title{
Stratosphere-Troposphere Coupling in a Relatively Simple AGCM: The Importance of Stratospheric Variability
}

\author{
EDWIN P. GERBER \\ Department of Applied Physics and Applied Mathematics, Columbia University, New York, New York \\ LORENZO M. POLVANI \\ Department of Applied Physics and Applied Mathematics, and Department of Earth and Environmental Sciences, \\ Columbia University, New York, New York
}

(Manuscript received 24 March 2008, in final form 30 September 2008)

\begin{abstract}
The impact of stratospheric variability on the dynamical coupling between the stratosphere and the troposphere is explored in a relatively simple atmospheric general circulation model. Variability of the model's stratospheric polar vortex, or polar night jet, is induced by topographically forced stationary waves. A robust relationship is found between the strength of the stratospheric polar vortex and the latitude of the tropospheric jet, confirming and extending earlier results in the absence of stationary waves. In both the climatological mean and on intraseasonal time scales, a weaker vortex is associated with an equatorward shift in the tropospheric jet and vice versa.

It is found that the mean structure and variability of the vortex in the model is very sensitive to the amplitude of the topography and that Northern Hemisphere-like variability, with a realistic frequency of stratospheric sudden warming events, occurs only for a relatively narrow range of topographic heights. When the model captures sudden warming events with fidelity, however, the exchange of information both upward and downward between the troposphere and stratosphere closely resembles that in observations. The influence of stratospheric variability on variability in the troposphere is demonstrated by comparing integrations with and without an active stratosphere. A realistic, time-dependent stratospheric circulation increases the persistence of the tropospheric annular modes, and the dynamical coupling is most apparent prior to and following stratospheric sudden warming events.
\end{abstract}

\section{Introduction}

Recent observational studies have demonstrated coupling between the stratosphere and troposphere in which stratospheric events originating as high as $10 \mathrm{hPa}$ are linked to changes in surface weather. On intraseasonal time scales (10-100 days), coupling is observed primarily in the winter and early spring, preferentially in the Northern Hemisphere, when and where the stratospheric polar vortex, or polar night jet, is most variable (Thompson and Wallace 2000; Charlton and Polvani 2007). A weakening and warming of the stratospheric polar vortex is associated with an equatorward shift of

Corresponding author address: Edwin P. Gerber, Center for Atmosphere Ocean Science, Courant Institute of Mathematics New York University, New York, NY 10012.

E-mail: gerber@cims.nyu.edu the tropospheric extratropical jet, and vice versa, and so is well characterized by the annular mode pattern of variability. Baldwin and Dunkerton (2001) further explored the temporal structure of the coupling by computing the northern annular mode (NAM) index independently at each height and found that weak (strong) stratospheric vortex events tend to precede negative (positive) shifts in the surface annular mode index by approximately 10 days. Furthermore, after such events, the troposphere tends to persist in the negative (positive) index state for two to three months. This behavior leads to the perhaps surprising result that, on monthly time scales, the NAM index at $150 \mathrm{hPa}$ provides a better prediction of the surface NAM index than the surface index itself (Baldwin et al. 2003).

These observations suggest that the stratosphere's influence on the troposphere may be effected by changes in the strength of the stratospheric polar vortex. Polvani and 
Kushner (2002, hereafter PK02) have explored the influence of polar vortex strength on the troposphere in a suite of experiments with an idealized model. They analyzed the impact of permanent changes to the thermal forcing of the stratosphere above $100 \mathrm{hPa}$ on the tropospheric jet: when the stratosphere polar vortex is made warmer and therefore weaker, the tropospheric extratropical jet shifts equatorward, consistent with the coupling observed on intraseasonal time scales in the atmosphere. It is unclear, however, if the causal relationship in their model - that is, that a perturbation in the stratosphere causes a shift in the tropospheric jet-is applicable to coupling on intraseasonal time scales. The polar vortex in the PK02 model was very strong and relatively steady, more representative of conditions in the Southern Hemisphere and thus inappropriate for the study of intraseasonal variability.

Plumb and Semeniuk (2003) showed, using a very simple stratosphere-only model, that the Baldwin and Dunkerton (2001) patterns suggesting downward influence could be generated by varying the amplitude of wave forcing at the lower boundary. Hence the origin of the seemingly downward propagating variability need not be in the stratosphere. In fact, the weak vortex composite patterns are simply composites around stratospheric sudden warming (SSW) events, and these are initiated by bursts of wave activity from the troposphere, as documented from observations by Polvani and Waugh (2004). A signal goes up in the form of wave fluxes and then later appears to come down in the annular mode index, but it is possible that tropospheric weather noise makes it difficult to see the signal in the lower atmosphere during the interim. As found by Baldwin and Dunkerton, the downward influence from the stratosphere is not generic, with some weak vortex events failing to impact the troposphere. The relatively short period of observations provided only $18 \mathrm{SSW}$ events, too small a sample to establish the statistical significance of the coupling.

In this paper, we address these concerns by constructing a simple atmospheric general circulation model (AGCM) with the salient features of stratosphere-troposphere coupling on intraseasonal time scales. The model is nearly identical to the one in PK02 but with surface topography added to generate stationary planetary waves that perturb the stratospheric polar vortex. With an appropriate topography, the model produces stratospheric sudden warmings with fidelity, capturing both the upward and downward exchange of information observed by Polvani and Waugh (2004) and Baldwin and Dunkerton (2001), respectively. Long integrations permit us to establish the downward influence of the stratosphere with greater statistical certainty. Comparison of integrations with and without an active stratosphere suggests that stratospheric variability influences the time scales of variability in the troposphere, increasing the persistence of the tropospheric annular mode. This increase in persistence is a consequence of the coupling surrounding SSW events and the slow thermal recovery of the polar vortex in the lower stratosphere. While the idealized nature of the model limits to some degree a direct comparison with the atmosphere, its computational efficiency makes it possible for us to more fully explore parameter space, and its simplicity provides greater clarity, suggesting that all of these phenomena are dynamical in origin and can be understood in terms of the interactions between planetary waves, synoptic eddies, and the mean flow.

The model specifications are outlined in section 2 . We explore the impact of changes in topography and stratospheric forcing on stratosphere-troposphere coupling in the time mean climate in section 3 . We find that the response of the troposphere to changes in the stratosphere is seemingly weakened by the addition of topography. Closer inspection of the original PK02 result, however, reveals unrealistic regime behavior in that model, yielding an overestimate of the stratosphere's impact. The addition of topography appears to eliminate that regime behavior, and we now find a more universal, albeit weaker, relationship between the strength of the polar vortex and the latitude of tropospheric jet. Stratosphere-troposphere coupling on intraseasonal time scales is analyzed in section 4 . In agreement with the work of Taguchi et al. (2001) and Taguchi and Yoden (2002), we find that the stratospheric polar vortex is quite sensitive to the shape and amplitude of the topographic forcing. Once the correct frequency of SSWs is established, however, the coupling on intraseasonal time scales detailed above falls into place. A discussion of our results and conclusions are found in section 5 .

\section{Model setup}

The model in this study is very similar to that used in PK02. It is a spectral dynamical core, developed by the Geophysical Fluid Dynamics Laboratory, that integrates the global primitive equations driven by idealized physics. All details of the thermal and momentum forcing are identical to PK02 and outlined in the appendix therein. For clarity, we summarize the key elements of the forcing here. An important simplification is in the temperature equation: in lieu of radiation and other physics schemes, the temperature is linearly relaxed to an analytic equilibrium profile that is independent of longitude. In the troposphere the equilibrium temperature profile is identical to that of Held and Suarez (1994) except for a factor to cause asymmetry in the temperature gradients between the two hemispheres 
to approximate solstice conditions. In the stratosphere, the equilibrium profile is set to the U.S. Standard Atmosphere (U.S. Committee on the Extension to the Standard Atmosphere 1976) everywhere except over the winter pole where a polar night jet is forced by a cold anomaly above $100 \mathrm{hPa}$. Here, from the pole to approximately $50^{\circ} \mathrm{N}$, the equilibrium temperature profile decreases linearly with height with fixed lapse rate $\gamma$. The polar vortex lapse rate $\gamma$ is a key free parameter explored in this paper and allows us to control the strength of the polar vortex. Momentum is removed from the system by a Rayleigh drag near the surface, as in Held and Suarez (1994). A linear drag is also applied at the top of the model (above $0.5 \mathrm{hPa}$ ) to approximate the wave drag of unresolved gravity waves. Analytic expressions for all of the above forcings are given in PK02.

The model in this study differs from PK02 in only one respect: the addition of surface topography. Surface topography creates stationary planetary waves that induce variability in the stratospheric vortex. As suggested by the linear theory of Charney and Drazin (1961), only the largest-scale planetary waves effectively propagate into the polar vortex. Thus we find that a simple topography is sufficient to create realistic variability in the stratosphere. The topography is specified, as in Reichler et al. (2005), by setting the surface geopotential height $\Phi_{0}$ as follows:

$$
\Phi_{0}(\lambda, \phi)=\left\{\begin{array}{lr}
g h_{0} \sin ^{2}\left(\frac{\phi-\phi_{0}}{\phi_{1}-\phi_{0}} \pi\right) \cos (m \lambda), & \phi_{0}<\phi<\phi_{1} \\
0, & \text { otherwise }
\end{array}\right.
$$

where $\lambda$ and $\phi$ refer to longitude and latitude, respectively, and $g$ is the acceleration of gravity. The key parameters explored in this study are $m$ and $h_{0}$, the topographic wavenumber and height, respectively. Parameters $\phi_{0}$ and $\phi_{1}$ are set to $25^{\circ}$ and $65^{\circ} \mathrm{N}$ so that the topography is centered at $45^{\circ}$. This is the latitude of the peak surface westerlies in the control integration, that is, without topography and with $\gamma=4 \mathrm{~K} \mathrm{~km}^{-1}$. The model is not too sensitive to the meridional structure of the topography provided that it impedes the flow of the tropospheric jet. ${ }^{1}$

A total of 28 integrations were performed to explore a three-dimensional parameter space consisting of the stratospheric polar vortex lapse rate $\gamma$, topographic wavenumber $m$, and topographic height $h_{0}$. The integrations are listed in Table 1 . Nearly all integrations

\footnotetext{
${ }^{1}$ The high latitude topography of Reichler et al. (2005) with $\phi_{0}=40$ and $\phi_{1}=80$ was relatively ineffective in generating upward propagating planetary Rossby waves.
}

were completed at triangular truncation 42 (T42) resolution, excepting two additional tests with the most realistic parameter settings. Here the model was run with half and double the resolution, triangular truncation 21 and 85 , respectively, to verify the robustness of our results. All integrations were performed with $40 \sigma$ levels in the vertical. The levels are spaced approximately evenly in log pressure height, as described in PK02, with 6 levels above $0.5 \mathrm{hPa}$ to provide sufficient resolution of the Rayleigh damping layer. We found that 2000 days was generally sufficient to establish the climatology of a model integration. ${ }^{2}$ As the rate of convergence was slower in integrations with greater stratospheric variability, key integrations were extended longer to reduce the uncertainty. Integration 9, with the most realistic stratosphere-troposphere coupling, was extended to 20000 days to obtain a large number of stratospheric sudden warming events.

\section{Climatological stratosphere-troposphere coupling}

We first explore the impact of changes to the stratospheric forcing and topography on the climatological relationship between the stratosphere and troposphere. The coupling between the mean polar vortex and tropospheric jet was investigated in PK02 and Kushner and Polvani (2004) in the absence of topography. Figure 1 illustrates the effect of topography on the time and zonal average zonal winds. The climatology is contrasted for two integrations with a strong polar vortex, with polar vortex lapse rate $\gamma=4 \mathrm{~K} \mathrm{~km}^{-1}$, and two integrations with a weak polar vortex $\gamma=2 \mathrm{~K} \mathrm{~km}^{-1}$. The integrations shown in the top panels have no topography, while those illustrated in the bottom panels have wavenumber $m=2$ topography of amplitude $h_{0}=$ $3000 \mathrm{~m}$. In the stratosphere, the addition of topography reduces the strength of the polar vortex. In the troposphere, topography pushes the tropospheric extratropical jet (marked by black arrows) equatorward so that it merges with the subtropical jet; the difference is particularly visible in the cases with the stronger polar vortex lapse rate, $\gamma=4 \mathrm{~K} \mathrm{~km}^{-1}$, shown on the left. The key result of $\mathrm{PK} 02$, that a decrease in the strength of the stratospheric polar vortex leads to an equatorward shift of the tropospheric jet, is clearly evident in the upper

\footnotetext{
${ }^{2}$ The 2000 days provided an uncertainty of less than half a degree on the estimates of the jet position and $\pm 2.5 \mathrm{~m} \mathrm{~s}^{-1}$ on stratospheric vortex strength in the most variable integrations. Integrations 7-9 were run for at least 5000 days to reduce the uncertainty in jet position to $0.15^{\circ}$ or less in each run.
} 
TABLE 1. Summary of model experiments: Integrations are organized in sequences in which a particular parameter is varied, and some integrations are listed more than once if they fit into more than one sequence. The integration $5^{*}$ is the control integration of the model without topography; the integration $9^{\dagger}$ has the most realistic coupling between the stratosphere and troposphere. All integrations listed here were run with $\mathrm{T} 42$ triangular truncation resolution, $40 \sigma$ levels in the vertical, and parameters $\phi_{0}=25$ and $\phi_{1}=65$ limiting the topography in latitude. The sampling times listed above are exclusive of a 300-day spin-up period at the beginning of each integration. The key parameter varied in each experiment is in boldface.

\begin{tabular}{|c|c|c|c|c|c|}
\hline Expt & Integration & Time & $\gamma$ & $m$ & $h_{0}$ \\
\hline \multirow[t]{6}{*}{ Vary $\gamma$, no topography } & 1 & 10000 & $\mathbf{0}$ & - & 0 \\
\hline & 2 & 10000 & 1 & - & 0 \\
\hline & 3 & 10000 & 2 & - & 0 \\
\hline & 4 & 10000 & 3 & - & 0 \\
\hline & $5 *$ & 10000 & 4 & - & 0 \\
\hline & 6 & 10000 & 5 & - & 0 \\
\hline \multirow[t]{4}{*}{ Vary $\gamma, m=2$} & 7 & 5500 & $\mathbf{0}$ & 2 & 3000 \\
\hline & 8 & 5500 & 2 & 2 & 3000 \\
\hline & $9^{\dagger}$ & 20000 & 4 & 2 & 3000 \\
\hline & 10 & 5200 & 6 & 2 & 3000 \\
\hline \multirow[t]{4}{*}{ Vary $\gamma, m=1$} & 11 & 2000 & $\mathbf{0}$ & 1 & 4000 \\
\hline & 12 & 2000 & 2 & 1 & 4000 \\
\hline & 13 & 4000 & 4 & 1 & 4000 \\
\hline & 14 & 2000 & 6 & 1 & 4000 \\
\hline \multirow[t]{5}{*}{ Vary $h_{0}, m=2$} & 15 & 2500 & 4 & 2 & 2000 \\
\hline & 16 & 5500 & 4 & 2 & 2500 \\
\hline & $9^{\dagger}$ & 20000 & 4 & 2 & 3000 \\
\hline & 17 & 3500 & 4 & 2 & 3500 \\
\hline & 18 & 2500 & 4 & 2 & 4000 \\
\hline \multirow[t]{7}{*}{ Vary $h_{0}, m=1$} & 19 & 2000 & 4 & 1 & 2000 \\
\hline & 20 & 2000 & 4 & 1 & 3000 \\
\hline & 13 & 4000 & 4 & 1 & 4000 \\
\hline & 21 & 4000 & 4 & 1 & 4250 \\
\hline & 22 & 2000 & 4 & 1 & 4500 \\
\hline & 23 & 2000 & 4 & 1 & 5000 \\
\hline & 24 & 2000 & 4 & 1 & 6000 \\
\hline \multirow[t]{4}{*}{ Vary $m, h_{0}=3000$} & 20 & 2000 & 4 & 1 & 3000 \\
\hline & $9^{\dagger}$ & 20000 & 4 & 2 & 3000 \\
\hline & 25 & 2000 & 4 & 3 & 3000 \\
\hline & 26 & 2000 & 4 & 4 & 3000 \\
\hline \multirow[t]{4}{*}{ Vary $m, h_{0}=4000$} & 13 & 4000 & 4 & 1 & 4000 \\
\hline & 18 & 2500 & 4 & 2 & 4000 \\
\hline & 27 & 2000 & 4 & 3 & 4000 \\
\hline & 28 & 2000 & 4 & 4 & 4000 \\
\hline
\end{tabular}

panels, but much more subtle in the lower panels, where topography is present.

We summarize the impact of the stratosphere on the troposphere in Fig. 2, where the strength of the polar vortex (left axis) and position of the tropospheric jet (right axis) are plotted as a function of stratospheric polar vortex lapse rate $\gamma$. The strength of the vortex is quantified by the speed of the time and zonal average zonal winds at $60^{\circ} \mathrm{N}$ and $10 \mathrm{hPa}$. Similar results are found if we more generally take the maximum wind speed in the vortex. The tropospheric jet latitude is determined by the maximum winds at $297 \mathrm{hPa}$, the model level with maximum tropospheric winds. ${ }^{3}$ Both with and without topography, we find that a weakening of the polar stratospheric vortex (smaller polar vortex lapse rate $\gamma$ ) leads to an equatorward shift in the maximum winds in the troposphere, as reported in PK02.

The amplitude of the shift, however, is far weaker in the case with topography. The regression coefficient between the strength of the polar vortex and the latitude of the tropospheric jet is $0.16^{\circ}\left(\mathrm{m} \mathrm{s}^{-1}\right)^{-1}$ without topography but only $0.031^{\circ}\left(\mathrm{m} \mathrm{s}^{-1}\right)^{-1}$ with topography. This implies that, in the model without topography, the tropospheric jet shifts on average $0.16^{\circ}$ for each $1 \mathrm{~m} \mathrm{~s}^{-1}$ increase in the strength of the stratospheric winds at $10 \mathrm{hPa}$, more than five times as much as the $0.031^{\circ}$ shift observed with an equivalent acceleration of the stratospheric vortex in the model with topography. The much weaker sensitivity of the tropospheric jet to the state of the stratosphere appears to be generic in the case with topography; a response of similar magnitude, regression coefficient $0.025^{\circ}\left(\mathrm{m} \mathrm{s}^{-1}\right)^{-1}$, is observed in a sequence of experiments with wavenumber $m=1$ topography (not shown).

\section{a. Regime behavior in the absence of topography}

At first glance, topography appears to substantially limit the impact of the stratosphere on the troposphere. It is possible that topography constrains the position of the tropospheric jet-in that the large mountains physically block the winds near $45^{\circ}$ - and this could limit the effect of the stratosphere, as observed in Fig. $2 b$. Closer inspection of the model without topography, however, reveals that the sensitivity observed by PK02 may be artificially high. Figure 2a suggests a nonlinear relationship between the polar vortex strength and jet latitude. The sensitivity is weaker for small or large values of $\gamma$, with a sharp jump between $\gamma=2$ and $4 \mathrm{~K} \mathrm{~km}^{-1}$.

This jump corresponds to a large reorganization of the tropospheric circulation, which can be seen in the top panels of Fig. 1. With a cold polar vortex (Fig. 1a, $\gamma=4 \mathrm{~K} \mathrm{~km}^{-1}$ ) the climatology is similar to that of

\footnotetext{
${ }^{3}$ This provides a measure of the location of the eddy-driven jet in the model. In most cases the subtropical, thermally driven jet and extratropical eddy-driven jets are largely coalesced. We measure the winds in the jet core to avoid complications due to topography at the surface.
} 


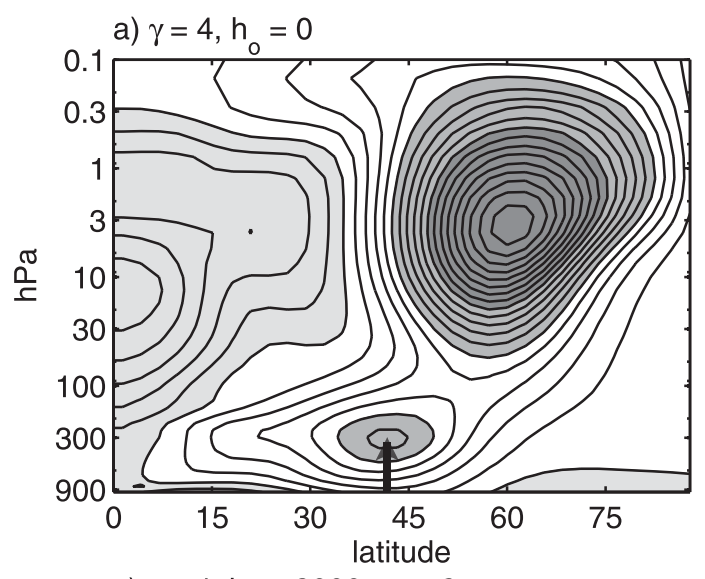

b) $\gamma=2, h_{0}=0$
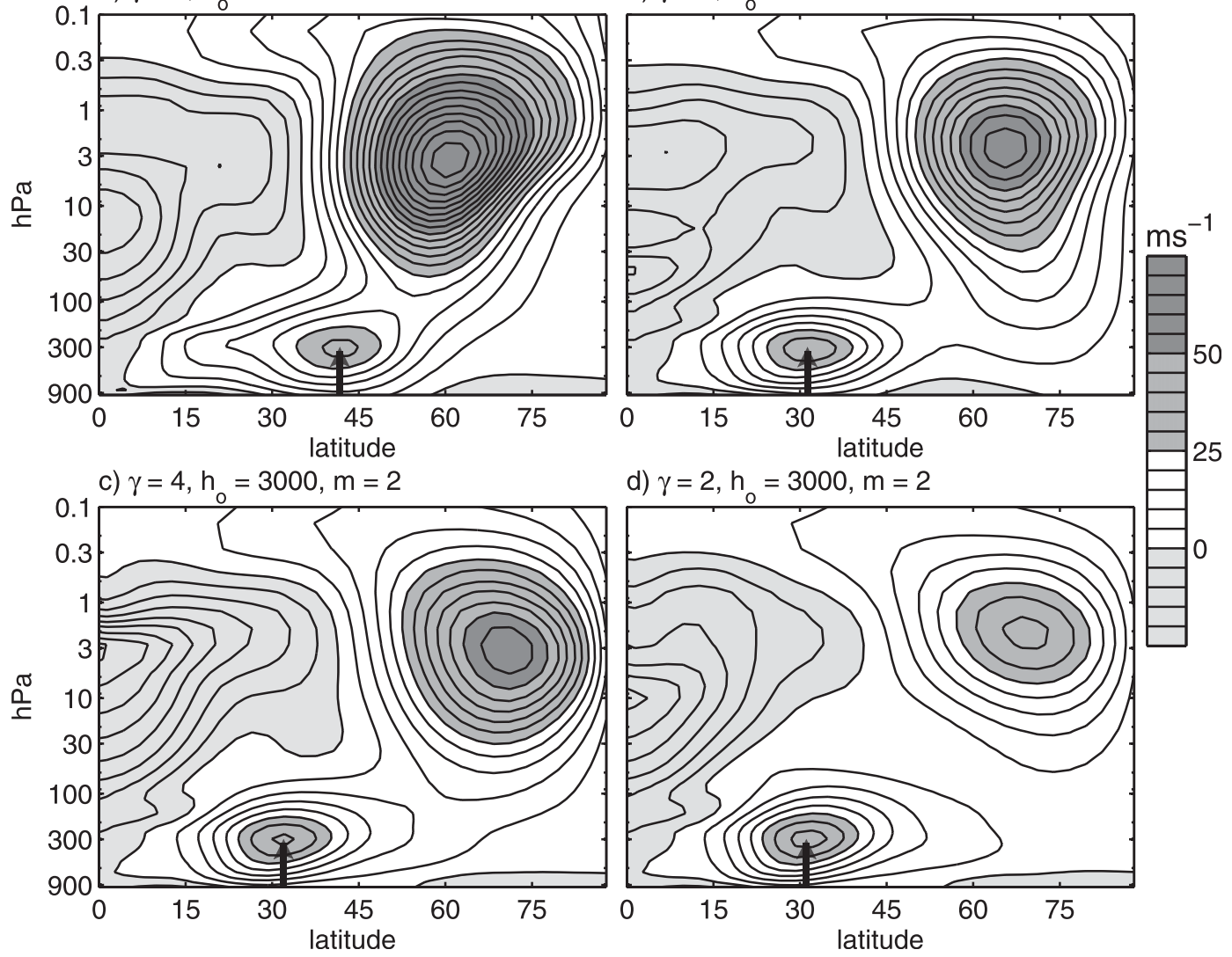

FIG. 1. Time and zonal mean winds with (left) strong stratospheric forcing (polar vortex lapse rate $\gamma=4 \mathrm{~K} \mathrm{~km}^{-1}$ ) and (right) weak stratospheric forcing $\left(\gamma=2 \mathrm{~K} \mathrm{~km}^{-1}\right)$ : (top) Integrations have no topography, as in PK02, and (bottom) integrations have wavenumber $m=2$ topography with amplitude $h_{0}=3000 \mathrm{~m}$. Contour interval is $5 \mathrm{~m} \mathrm{~s}^{-1}$. As listed in Table 1, integrations are (a) 5, (b) 3, (c) 9, and (d) 8 .

the atmosphere with an extratropical jet at approximately $43^{\circ} \mathrm{N}$, separated from a more baroclinic subtropical jet in lower latitudes. With a warmer polar vortex (Fig. 1b, $\gamma=2 \mathrm{~K} \mathrm{~km}^{-1}$ ), the main extratropical jet-the surface westerlies-are near $32^{\circ}$ and coalesced with the subtropical jet, and a second region of surface westerlies appears in the high latitudes near $80^{\circ}$. In the strong vortex state, the polar winds appear to connect to the extratropical jet; in the weak vortex state, the polar winds bend toward the second high-latitude region of westerlies. This suggests that the model is switching between one and two surface westerly jet regimes, depending on the coupling with the stratosphere.

Further evidence for regimes can be seen in Fig. 3, a close inspection of the model without topography and $\gamma=3 \mathrm{~K} \mathrm{~km}^{-1}$ (integration 4 in Table 1). The Hovmöller diagram of the 10-day averaged zonal average zonal wind near the surface $(\sigma=0.945)$ as a function of time shows a seemingly chaotic vacillation between two states. One state has strong surface winds centered near $43^{\circ}$, and the other has weaker winds centered around $32^{\circ}$ and evi- dence of a second band of westerlies in the extreme high latitudes, characteristic of the climatologies of the $\gamma=4$ and $\gamma=2 \mathrm{~K} \mathrm{~km}^{-1}$ integrations, respectively.

Lee (1997) discusses the abrupt transition between one and two jet regimes as the width of a baroclinic zone is increased in a channel model. The PK02 model is based on the Held and Suarez (1994) forcing but, to give the model a more realistic stratosphere, the tropopause was lowered relative to the standard model. This has been shown to shift the tropospheric jets equatorward (Williams 2006) and thus creates a fairly wide baroclinic zone with enough space for two jets, putting the model in an intermediate regime. With a weak polar vortex, a weak second jet forms near the pole, coupling to the vortex above. But for a strong vortex, interactions between the vortex and the primary extratropical jet become strong enough to displace the tropospheric jet poleward past the point where two regions of westerlies can coexist. A regime transition takes place, and there is a substantial reorganization of eddy activity in the troposphere. Further discussion of regime behavior in the 

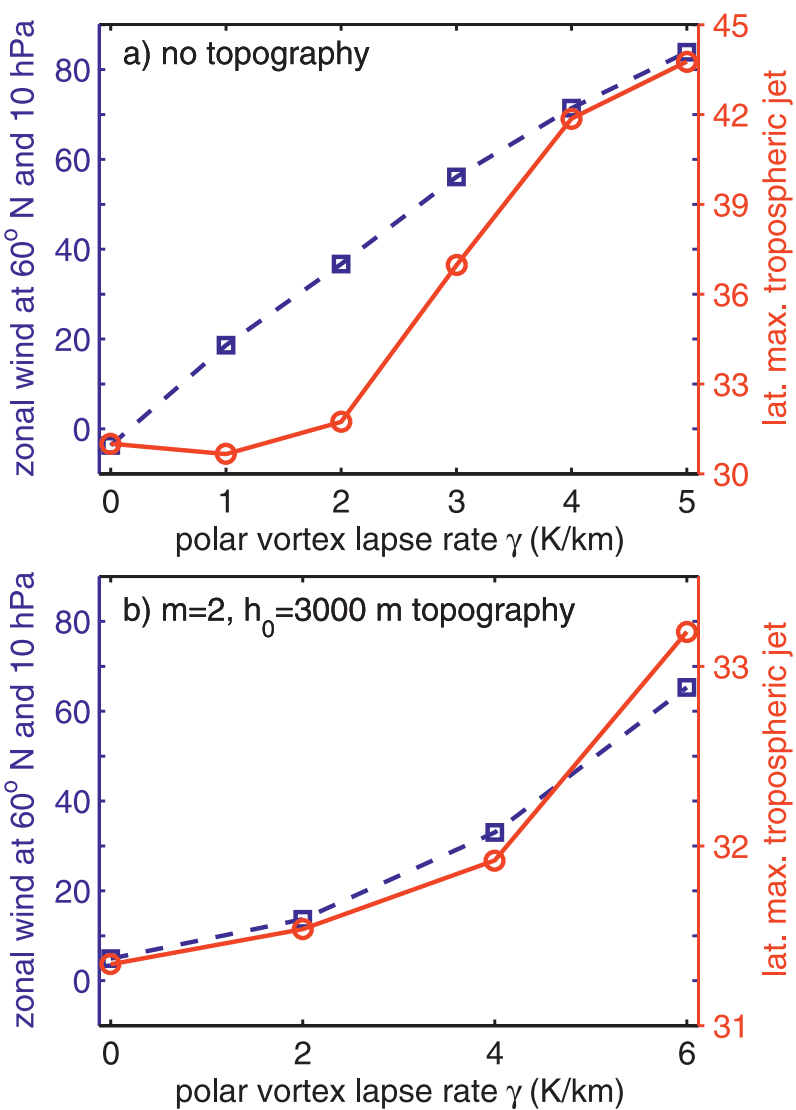

FIG. 2. Impact of topography on the relationship between strength of the stratospheric polar vortex and position of the tropospheric jet. The time and zonal average zonal winds at $60^{\circ} \mathrm{N}$ and $10 \mathrm{hPa}$ (blue dashed curve, left axes) and the latitude of the maximum tropospheric winds at $297 \mathrm{hPa}$ (red curve, right axes) are plotted as a function of $\gamma$ for (a) the model without topography and (b) with wavenumber $m=2$ topography of amplitude $h_{0}=3000 \mathrm{~m}$. The parameter $\gamma$ is the lapse rate $\left(\mathrm{K} \mathrm{km}^{-1}\right)$ of the equilibrium temperature profile above $100 \mathrm{hPa}$ over the pole and therefore controls the forcing of the polar vortex. Here, (a) is based on integrations $1-6$ in Table 1 and (b) integrations 7-10.

model without topography, with a focus on its effect on stratosphere-troposphere coupling, can be found in Chan and Plumb (2009).

The addition of topography appears to eliminate the two jet state, and hence the regime behavior. With topography, there is a single region of surface westerlies for all values of $\gamma$, and the polar vortex couples down to the single tropospheric jet. Hence, the response of the troposphere to changes in stratospheric forcing is weaker but now more readily compared with the observations. The amplitude of the jet shift, typically $1^{\circ}-2^{\circ}$, is quantitatively similar with composites based on strong and weak vortex winters constructed by Baldwin (2003), where differences in vortex strength $\left(>40 \mathrm{~ms}^{-1}\right)$ were also of similar magnitude.

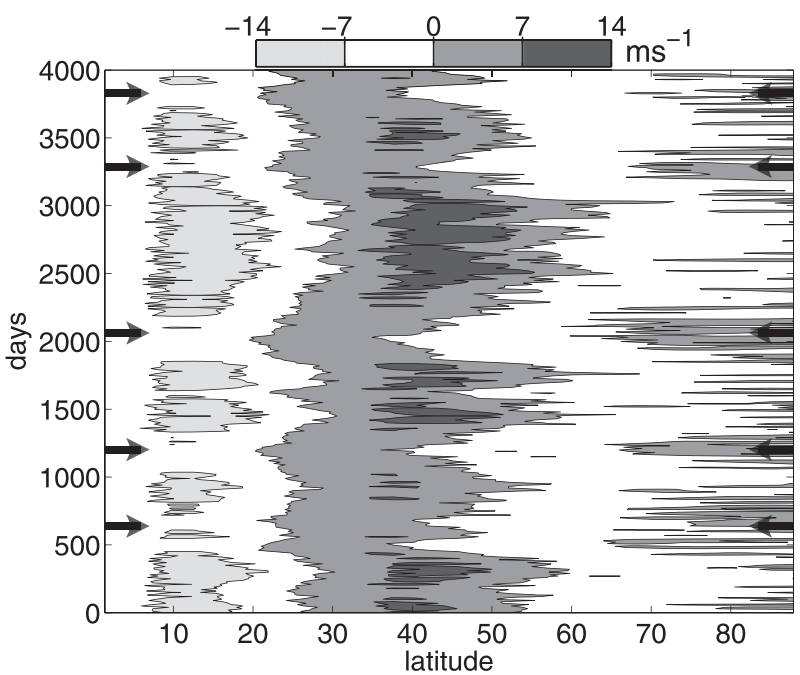

FIG. 3. Composite of the 10-day-average zonal-average zonal wind near the surface $(\sigma=0.945)$ for 4000 days in an integration of the model without topography and $\gamma=3 \mathrm{~K} \mathrm{~km}^{-1}$. Black arrows mark the times when the model is in the double jet state, similar to the climatology of the model with $\gamma=2 \mathrm{~K} \mathrm{~km}^{-1}$. At these times, the primary band surface westerlies are weak and shifted equatorward to approximately $32^{\circ} \mathrm{N}$, and a second band of westerlies appears near the pole. At other times the surface winds are similar to those of the $\gamma=4 \mathrm{~K} \mathrm{~km}^{-1}$ integration, with one strong band of westerlies near $43^{\circ} \mathrm{N}$.

\section{b. Robustness of the relationship between polar vortex strength and tropospheric jet position}

The addition of topography to the model provides a wider parameter space to test the relationship between stratospheric vortex strength and the location of the midlatitude jet. The relationship is shown in Fig. 4 for two additional series of experiments. In the top panel, the stratospheric forcing is fixed (lapse rate $\gamma=$ $4 \mathrm{~K} \mathrm{~km}^{-1}$ ) and the amplitude $h_{0}$ of a wavenumber $m=2$ topography profile is varied. As the amplitude of the topography is increased, the stratospheric vortex is weakened and the tropospheric jet shifts equatorward. The regression between the vortex strength and jet latitude, $0.16^{\circ}\left(\mathrm{m} \mathrm{s}^{-1}\right)^{-1}$, is much stronger than in Fig. $2 \mathrm{~b}$, roughly five times the sensitivity observed when the changes are driven by changes to the stratospheric forcing alone. ${ }^{4}$ The same relationship between vortex

\footnotetext{
${ }^{4}$ These sensitivities are more similar to that in the original PK02 model (Fig. 2a), but we do not see evidence of a simple one to two jet regime transformation in the cases with varying topography. These sensitivities are comparable when the amplitude $h_{0}$ is varied for fixed wavenumber $m=1$ topography, or when the wavenumber $m$ is varied with topography of fixed amplitude $h_{0}=3000 \mathrm{~m}$ (not shown).
} 

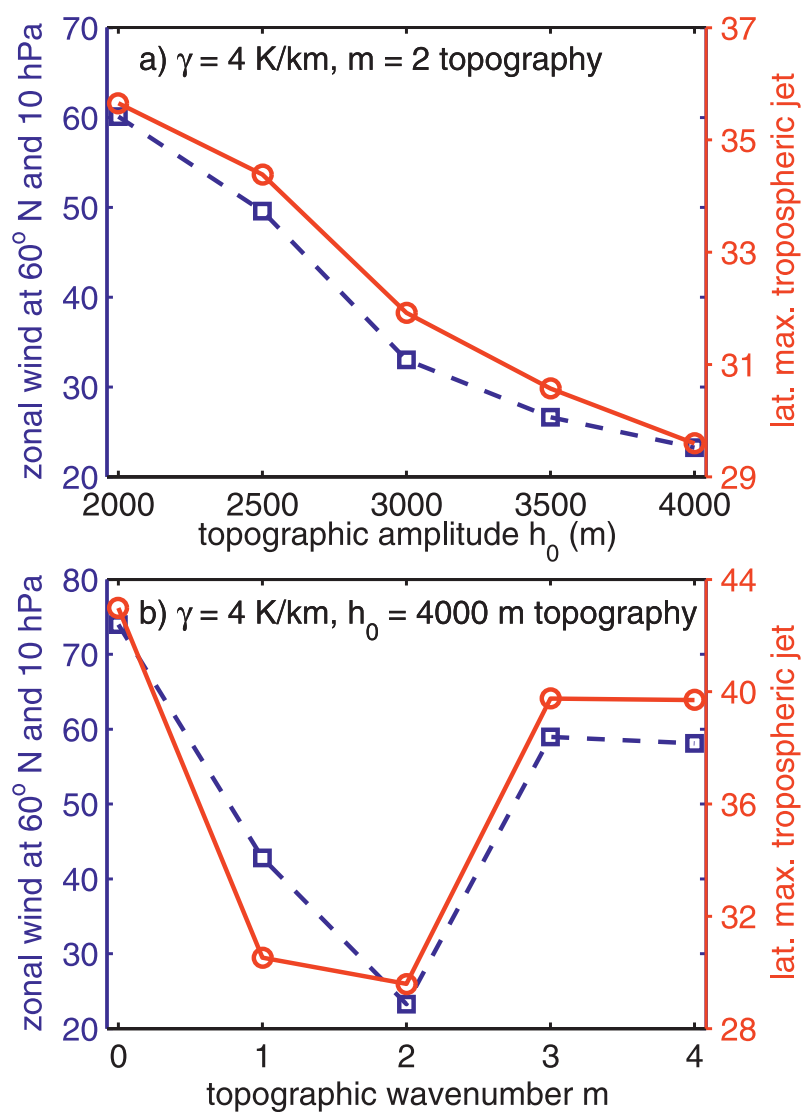

FIG. 4. Impact of the amplitude and wavenumber of the topography on the stratospheric vortex and tropospheric jet. As in Fig. 2 but in (a), the topographic amplitude $h_{0}$ of wavenumber $m=2$ orography is varied for five integrations with the same stratospheric forcing, $\gamma=4 \mathrm{~K} \mathrm{~km}^{-1}$ (integrations 15, 16, 9, 17, and 18 in Table 1) and in (b), the topographic wavenumber $m$ is varied for topography of fixed amplitude $h_{0}$ with fixed stratospheric forcing, $\gamma=4 \mathrm{~K} \mathrm{~km}^{-1}$ (integrations 5, 20, 9, 25, and 26; the "wavenumber 0" integration has no topography).

strength and the tropospheric jet position is found in Fig. 4b, where the stratospheric forcing and amplitude of the topography are fixed $\left(\gamma=4 \mathrm{~K} \mathrm{~km}^{-1}\right.$ and $\left.h_{0}=4000 \mathrm{~m}\right)$ and the wavenumber $m$ governing the structure of the topography is varied. Here the regression coefficient between the stratospheric winds and position of the tropospheric jet is $0.30^{\circ}$ $\left(\mathrm{m} \mathrm{s}^{-1}\right)^{-1}, 10$ times the sensitivity observed when the stratosphere was perturbed alone. All of these results suggests that the strength of the stratospheric vortex is well correlated with the position of the tropospheric jet—but does not necessarily cause the tropospheric jet to shift.

Rather, we argue that the processes influencing the position of the tropospheric jet also determine the strength of the polar vortex. In the stratosphere, the results in Fig. 4 can be understood in terms of the planetary wave flux into the polar vortex: increased wave flux leads to a stronger wave drag and hence a weaker vortex. For topography of fixed wavenumber, increased amplitude at the surface creates larger standing waves at the tropopause and therefore a stronger upward wave flux into the vortex. For topography of fixed amplitude, the results are in keeping with the linear theory of Charney and Drazin (1961): only wavenumbers 1 and 2 can effectively propagate into the polar vortex, and there is a weaker wave flux for wavenumbers 3 and 4 .

In the troposphere, larger topography increases the mountain drag, impacting the momentum balance in the jet directly. This could explain much of the shift in the jet seen in the top panel of Fig. 4 but perhaps not as much in the lower panel. There is only a dramatic equatorward shift of the tropospheric jet with $m=1$ and 2 , despite the fact that total mountain height is the same as in integrations with $m=3$ and 4 . In fact, the climatology is quite similar in integrations with higher wavenumber topography and with no topography at all. Topography also modifies the stationary and transient eddies, indirectly impacting the momentum balance in the troposphere. This "eddy mediated" response may provide a common link to the response to changes in the stratosphere, that is, parameter $\gamma$. As discussed by Song and Robinson (2004) and Kushner and Polvani (2004), tropospheric eddies are key to explaining the response of the tropospheric jet to strengthening/weakening of the vortex in the cases without topography.

In summary, we have found a very robust relationship between the position of the tropospheric jet and the strength of the polar vortex in the climatological mean. Irrespective of which parameters are varied, a weaker stratospheric polar vortex is associated with an equatorward shift of the tropospheric jet and vice versa, although the constant of proportionality is very sensitive to the manner in which the strength of the vortex is varied. Given the robustness of this coupled response across all integrations, we now turn to the question of coupling on intraseasonal time scales. Does one find the same coupling between stratosphere and troposphere within a single integration, in particular, surrounding stratospheric sudden warming events, the natural fluctuations in vortex strength internally produced by the system?

\section{Intraseasonal stratosphere-troposphere coupling}

For meaningful coupling between the stratosphere and troposphere on intraseasonal time scales, a model must reasonably simulate stratospheric sudden warming events. SSWs occur when a large flux of planetary scale waves propagates up the vortex and break at higher levels. As shown by Taguchi and Yoden (2002), the stratosphere is 
very sensitive to planetary wave forcing from the troposphere, and SSW-like behavior in their model was only observed for a narrow range of mountain heights. In this section, we first seek the surface topography that produces the most realistic sudden warming behavior, with particular attention to the character and frequency of the model's warming events. On average, a sudden warming occurs every other winter in the Northern Hemisphere (Charlton and Polvani 2007). If we consider the length of the extended November-March (NDJFM) season, this suggest that we should aim for one SSW every 200-300 days in a perpetual January integration. While we have three control parameters-polar vortex lapse rate $\gamma$, topographic wavenumber $m$, and topographic amplitude $h_{0}$-we use them only to shape the variability of the stratosphere. We then show that all salient features of the coupling between the stratosphere and troposphere on intraseasonal time scales follow naturally once the model exhibits realistic stratospheric variability.

\section{a. Stratospheric sudden warming events}

The variability of the stratospheric polar vortex was surveyed as a function of the three free parameters in the model. The relative independence of the parameters limits the possible combinations that provide realistic variability. For example, the vortex lapse rate $\gamma$ sets the strength of the unperturbed vortex and, therefore, the maximum winds in the SSW cycle. It provides a convenient switch to limit all stratospheric variability but is constrained by observations independently of the topographic parameters $m$ and $h_{0}$. We briefly summarize the key findings, beginning with the most constrained parameter and ending with the most flexible.

- Sensitivity to equilibrium polar vortex lapse rate $\gamma$. Parameter $\gamma$ controls the thermal state of the unperturbed polar vortex and thus the strength of the winds. Limited variability is found with all topographic parameters for small $\gamma$, possibly because weak potential vorticity gradients do not allow sufficient wave activity to propagate into the vortex. For very large values of $\gamma$, the vortex can become increasingly variable with certain topographic configurations but the mean winds always increase faster than the variance. Hence, the World Meteorological Organization criterion for a SSW, that the zonal mean zonal wind at $60^{\circ} \mathrm{N}$ and $10 \mathrm{hPa}$ reverse, is never satisfied. Northern Hemisphere-like variability is thus found only at the intermediate value $\gamma=4 \mathrm{~K} \mathrm{~km}^{-1}$.

- Sensitivity to topographic wavenumber $m$. Wave propagation theory imposes a tight constraint on parameter $m$, as only large-scale planetary waves effectively propagate into the polar vortex (Charney and Drazin 1961). We find the most realistic behavior for wavenumber $m=2$ topography, in contrast to Taguchi and Yoden (2002), who found optimal variability with $m=1$. In our model, wavenumber $m=$ 1 stationary waves tend to systematically erode the polar vortex, constantly stripping away filaments of potential vorticity. With $m=2$ topography, we find the slow build up and rapid splitting of the vortex, as observed during SSW events. The strength of the polar vortex is extremely intermittent with $m=3$ and $m=4$; there are occasional wavenumber 2 warmings (wavenumber 2 is generated through nonlinear interactions between the topography and tropospheric jet), but they are far too infrequent, even for extremely large topographic amplitudes.

- Sensitivity to topographic amplitude $h_{0}$. Parameter $h_{0}$ is the key free variability to tune the frequency of SSW events. The sensitivity to topographic height is in agreement with the Taguchi and Yoden (2002) study. As illustrated in Fig. 5a, with weak topography, the stratosphere exhibits infrequent, albeit extremely strong, sudden warming events. [Even without any direct stationary wave forcing at the surface, SSWs can be generated by the natural variability, at a frequency of order one per 10000 days (Scinocca and Haynes 1998; Kushner and Polvani 2005).] For intermediate values (Fig. 5b), the stratosphere approaches a Northern Hemisphere-like state of variability, with events occurring on average every 200 to 300 days. For larger amplitude (Fig. 5c), the vortex is continually eroded by planetary wave fluxes from below and, therefore, exhibits limited variability. With $m=2$, the interval in $h_{0}$ for which there are realistic SSWs is narrow, between 2500 and $3500 \mathrm{~m}$. With wavenumber 1 the vortex is even more sensitive: it is relatively strong with $h_{0}=4000 \mathrm{~m}$ and largely destroyed with $h_{0}=4500 \mathrm{~m}$, but with seemingly no clear SSW regime in between.

Sensitivity of these results to model resolution was tested with the parameter settings that produced the most realistic stratospheric variability at $\mathrm{T} 42$ resolution, $\gamma=4, m=2$, and $h_{0}=3000$. (Winds from this integration are pictured in Fig. 5b.) At T21 spectral truncation, which corresponds to a $5.6^{\circ}$ grid spacing at the equator, the model exhibits no sudden warmings over a 5000-day test period. Model integrations at T42 and T85 spectral truncation (grid resolutions of $2.8^{\circ}$ and $1.4^{\circ}$, respectively), however, exhibit similar variability with on average one warming event every 200-300 days. The tropospheric jet is not well formed at T21 resolution (Gerber et al. 2008b), which would affect the stationary waves fluxes into the stratosphere. This could likely change the 


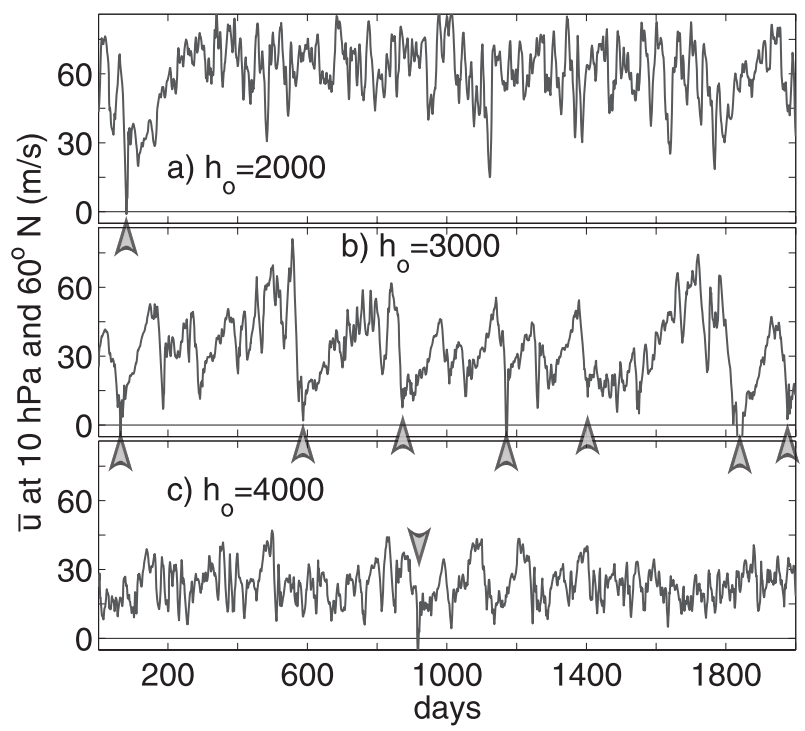

FIG. 5. Zonal-average zonal wind $\bar{u}$ at $10 \mathrm{hPa}$ and $60^{\circ} \mathrm{N}$ as a function of time for three integrations with $\gamma=4$ and wavenumber $m=2$ topography of amplitude (a) $h_{0}=2000$, (b) $h_{0}=3000$, and (c) $h_{0}=4000$. Major and minor warming events are marked by arrows in each integration; by the WMO definition, the winds must reverse direction at this level for a major warming. It becomes hard to objectively define warming events in the weak vortex state with large topography. A similar picture, but constructed with the 10 hPa NAM index, is virtually indistinguishable owing to the high correlation between the index and the zonal winds at this point in the vortex (not shown). Integrations are (a) 15, (b) 9, and (c) 18, as listed in Table 1.

frequency of events but does not explain their total disappearance; SSWs are found over a range of different topographic configurations at T42 resolution. This suggest that sufficient horizontal resolution in the stratosphere may be important, as found by Scott et al. (2004).

In the stratosphere, the SSW events, although initially large-scale wavenumber 2 splits of the vortex, depend on small-scale interactions in the decay phase when the split vortex is sheared apart. A sample event at T42 resolution is illustrated in Fig. 6. The initially large and strong polar vortex $(t=-14)$ is at first slowly stretched out $(t=-7)$ in the week leading up to the SSW. After it splits $(t=0)$, the vortex is rapidly sheared apart, leading to irreversible mixing of potential vorticity and a sharp drop in the vortex strength. The shearing and mixing is essential to produce the sawtooth pattern in Fig. 5b, quickly destroying the vortex so that it must grow again on the slow thermal relaxation time scale.

\section{b. Structure of the annular modes}

For the choice $\gamma=4, m=2$, and $h_{0}=3000$, which produces the most realistic stratospheric variability—both
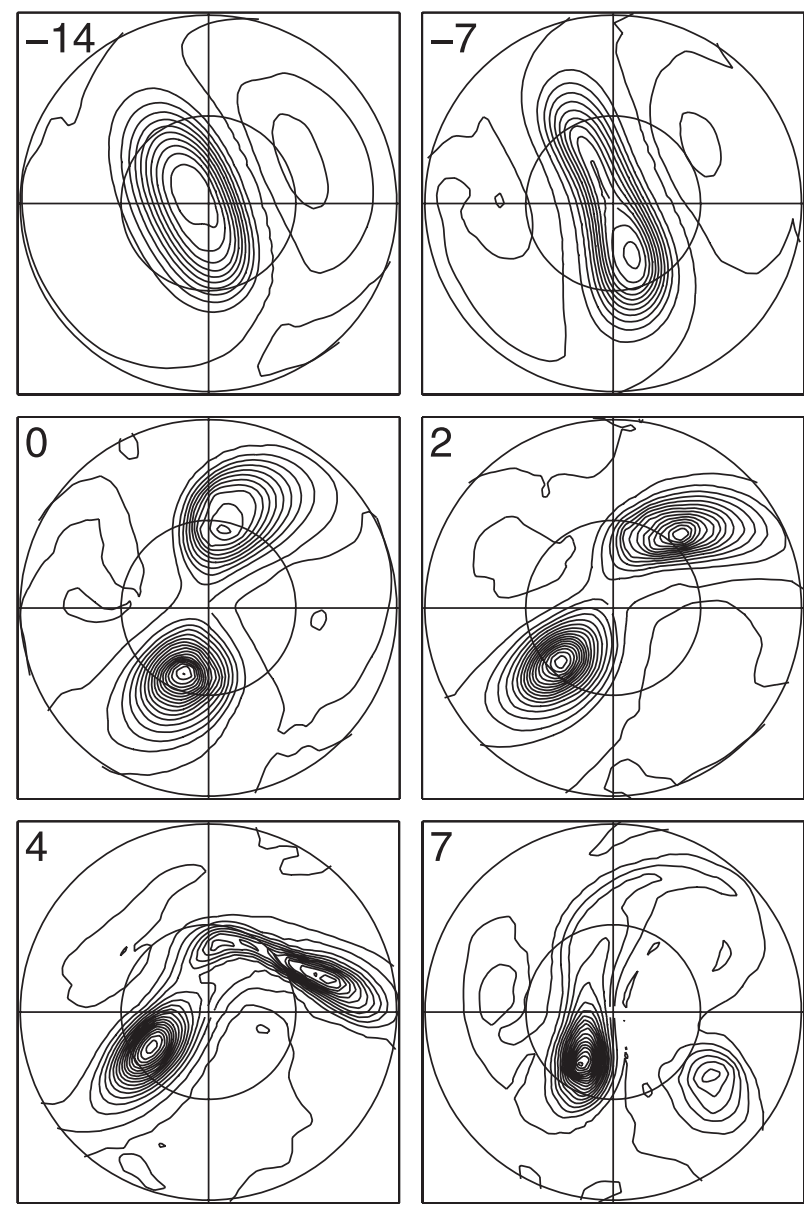

FIG. 6. Sample stratospheric sudden warming in the control simulation. The Lait potential vorticity on the $840-\mathrm{K}$ isentropic surface is shown from $30^{\circ} \mathrm{N}$ to the pole: contour interval $20 \mathrm{PVU}$. The onset date (day 3691) was determined by the time when the NAM index at $10 \mathrm{hPa}$ crossed the -2 standard deviation threshold: time relative to onset is marked in the upper left corner of each panel.

in the frequency and structure of sudden warming eventswe now focus on the coupling between the stratosphere and troposphere on intraseasonal time scales. A first order measure of that coupling is the structure of the annular mode. Figure 7 shows the first empirical orthogonal functions of the daily zonal average zonal wind as a function of pressure and latitude for two integrations (top) without topography as in PK02 and (bottom) with the optimal topographic forcing. Contours mark the climatological zonal winds and shading the EOFs. The EOF pattern in the model without topography indicates a vacillation of the extratropical jet that is largely confined to the troposphere. The lower panel shows the same EOF, but now in the model with an active stratosphere. The variability in the troposphere is the same relative to the mean jet structure, a meridional vacillation of the jet, but now the EOF extends deep into the 

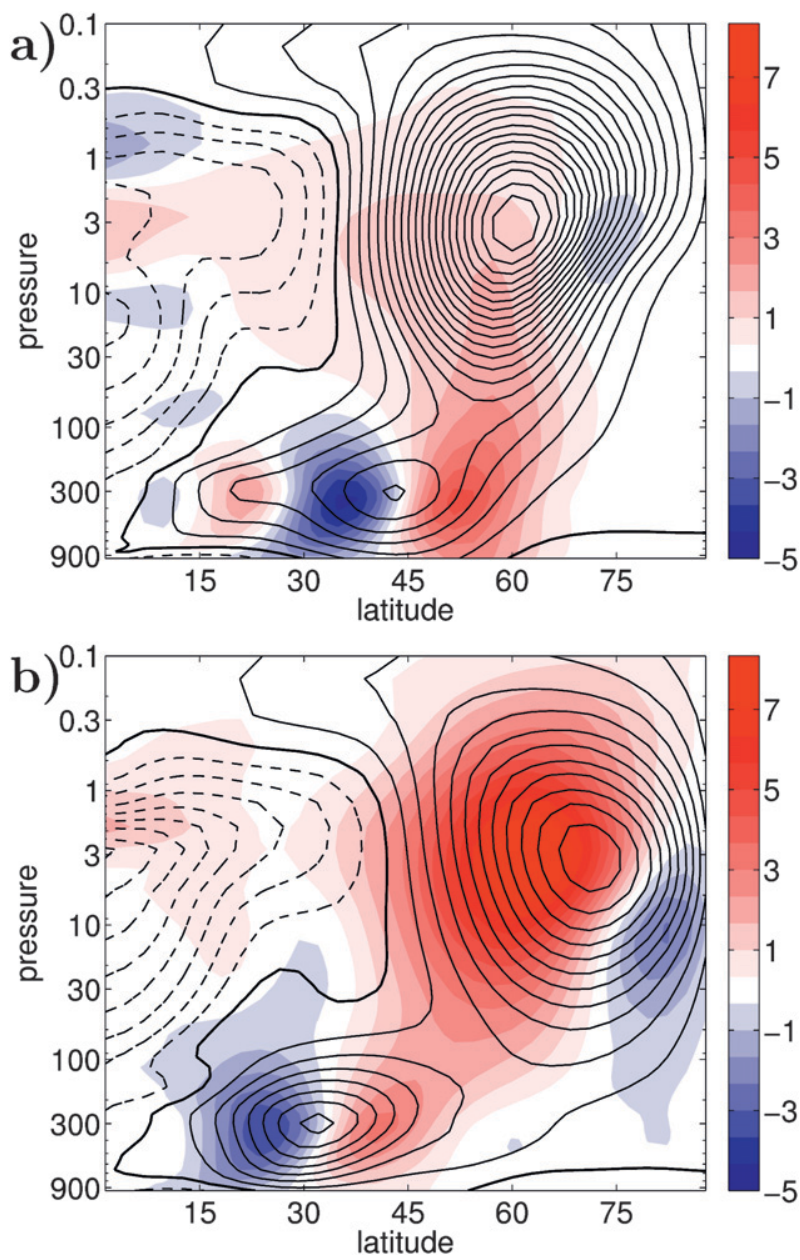

FIG. 7. The annular mode as a function of pressure and height for the model (a) without topography (integration 5) and (b) with wavenumber $m=2$ topography of amplitude $h_{0}=3000 \mathrm{~m}$ (integration 9). The same strong stratospheric vortex is forced in both cases with $\gamma=4 \mathrm{~K} \mathrm{~km}^{-1}$. Contours mark the climatological zonal winds (contour interval $5 \mathrm{~m} \mathrm{~s}^{-1}$, negative contours dashed, the zero contour in bold) and the color shading denotes the annular mode EOF, with units of meters per second corresponding to a positive one standard deviation anomaly. The two-dimensional annular mode is defined as the first EOF of the pressure and area weighted zonal-average zonal winds from the equator to the pole.

stratosphere, characterizing the large-scale strengthening and weakening of the polar vortex. This EOFs suggest the same relationship between the troposphere and stratosphere documented for the time mean in the previous section: a weaker polar vortex is associated with an equatorward shift of the tropospheric jet.

These two EOFs compare favorably with a similar measure of the observed variability in the Southern and Northern Hemispheres, Figs. 1a and 1b of Thompson and Wallace (2000). The annular modes penetrate much deeper into the stratosphere in the Northern Hemisphere where there is more significant coupling between the troposphere and stratosphere on intraseasonal time scales because of sudden stratospheric warmings.

\section{c. Upward and downward exchange of information}

Next, we turn our attention to the details of coupling between the troposphere and stratosphere, as diagnosed by Baldwin and Dunkerton (2001) and Polvani and Waugh (2004). Statistics are constructed from a 20000 day integration of the model with the optimal forcing parameters. This long integration provides $83 \mathrm{SSW}$ events, identified using the 10-hPa NAM as in Baldwin and Dunkerton (2001). The NAM at each level is defined as the first EOF of the zonally averaged zonal wind. The onset day of an event is defined as the first instance when the $10-\mathrm{hPa}$ NAM index crosses a -2.0 standard deviation threshold, ${ }^{5}$ subject to the additional requirement that events be separated by a recovery period of at least 45 days. The extended recovery period was chosen in light of the longer time scales observed in the model.

Figure 8a shows a composite of the NAM index as a function of time and height. The black contours mark areas where the index is statistically distinct from zero with $95 \%$ certainty. Our simple model reproduces the key finding of Baldwin and Dunkerton (2001), that a breakdown of the polar vortex at $10 \mathrm{hPa}$ (indicated by a strong negative annular mode index) precedes a persistent shift of the tropospheric annular mode toward a low index state, that is, an equatorward shift of the jet. Figure $8 \mathrm{~b}$ is a composite of the anomalous, latitude-weighted $20^{\circ}-90^{\circ}$ average meridional heat fluxes at $96 \mathrm{hPa}$,

$$
\mathcal{H}=\alpha \int_{20}^{90} \overline{v^{\prime} T^{\prime}} \cos \phi d \phi
$$

where an overbar denotes a zonal average, prime a deviation therefrom, and $\alpha^{-1}=\int_{20}^{90} \cos \phi d \phi$ is a normalization constant. Here, $\mathcal{H}$ is proportional to the upward flux of wave activity, the vertical component of the Eliassen-Palm wave flux. The solid line marks the integral of $\mathcal{H}$ over the 40 days prior to a given day, for the vortex responds to the integrated heat flux (Newman et al. 2001). As in Polvani and Waugh (2004), the stratospheric warming events at $10 \mathrm{hPa}$ are preceded by a burst of upward wave activity. Analysis of specific events (not shown) indicates that the composite is a fair representation of individual sudden warming events.

\footnotetext{
${ }^{5}$ A threshold of -3.0 was used by Baldwin and Dunkerton (2001). We found that the -2.0 threshold was more appropriate for identifying SSW events (as defined by Charlton and Polvani 2007) in this idealized model.
} 


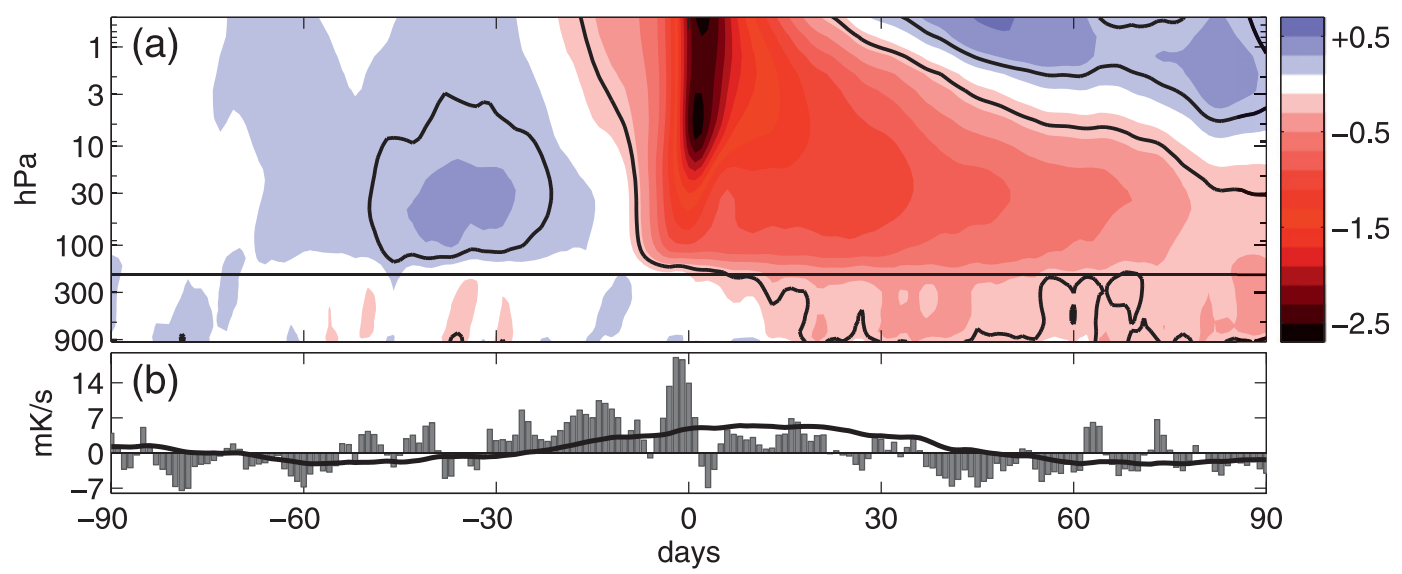

FIG. 8. (a) Composite of the annular mode index as a function of pressure and lag, based on 83 stratospheric sudden warming events determined by the day that the NAM index at $10 \mathrm{hPa}$ drops below -2 standard deviations. Black contours mark areas significantly different from zero with $95 \%$ confidence. (b) Composite of $\mathcal{H}$, the $20^{\circ}-90^{\circ}$ average meridional heat flux at $96 \mathrm{hPa}$, as defined in (2), for the same events: $\mathcal{H}$ is proportional to the upward flux of wave activity into the vortex. The solid line denotes the mean of $\mathcal{H}$ over the 40 previous days.

The large sample size, more than 80 events, allows us to establish statistical significance to all key features of the coupling. The positive NAM index in the lower and midstratosphere in the period preceding the warming event suggests a preconditioning of the polar vortex. As seen in observations, potential vorticity gradients in the stratospheric vortex must be great enough to permit propagation of wave activity from the troposphere for a significant warming (Charlton and Polvani 2007). The stratospheric vortex splits abruptly, nearly synchronously at all levels (Matthewman et al. 2009), as seen in the sharp drop to negative NAM index values in the stratosphere just before lag zero. After the warming, the vortex recovers slowly on the time scale of the thermal forcing. The recovery is faster at upper levels, giving the impression of downward propagation. The upper levels of the vortex are farther from their thermal equilibrium temperature than lower levels and thus experience a stronger cooling initially. Perhaps more importantly, the upper vortex is shielded from planetary wave propagation by weak winds in the lower stratosphere and is therefore able to recover faster and reach a colder than average state. The response of the troposphere lags the stratospheric NAM index by approximately two weeks. This is somewhat slower than in observations, but in keeping with the internal variability of the idealized model. The time scale of the NAM in the troposphere, to first order, quantifies the time scale at which the extratropical jet shifts in latitude and is set by interactions between the mean flow and eddy forcing (Gerber and Vallis 2007). The observed time scale is $O$ (15 days) (Baldwin et al. 2003), while in this idealized model it is between 20 and 30 days.

\section{d. Impact of stratospheric variability on the troposphere}

The tropospheric annular mode remains in the negative phase for an extended period after a sudden warming event in both observations (Baldwin and Dunkerton 2001) and our model. Figure 8 indicates the tropospheric jet persists on the slow thermal recovery time scale associated with the lower stratosphere, which is two or three times greater than the tropospheric annular mode time scale, which quantifies the period of typical excursions of the tropospheric jet. Does this coupling with the stratosphere after SSW events play a significant role in tropospheric variability?

Figure 9 demonstrates that variability in the stratosphere can increase the overall time scale of variability in the troposphere, as found earlier with a comprehensive GCM by Norton (2003). In Fig. 9a, we show the autocorrelation function of the midtropospheric annular mode index for four integrations that differ only in the stratospheric forcing. The equilibrium polar vortex lapse rate parameter $\gamma$ allows us to turn on (off) the stratospheric coupling by strengthening (weakening) the polar vortex. For small values of $\gamma$, the polar vortex is weak and varies little, while for large values of $\gamma$ the polar vortex is strong enough to permit significant planetary wave propagation - and so exhibit the sudden warming events documented in Fig. 8. The autocorrelation function indicates the memory, or persistence, of the model's annular mode. With an active stratosphere $(\gamma=$ 4 or $6 \mathrm{~K} \mathrm{~km}^{-1}$ ), excursions of the jet persist longer on average than with a passive stratosphere $(\gamma=0$ or 2 $\mathrm{K} \mathrm{km}^{-1}$ ). 

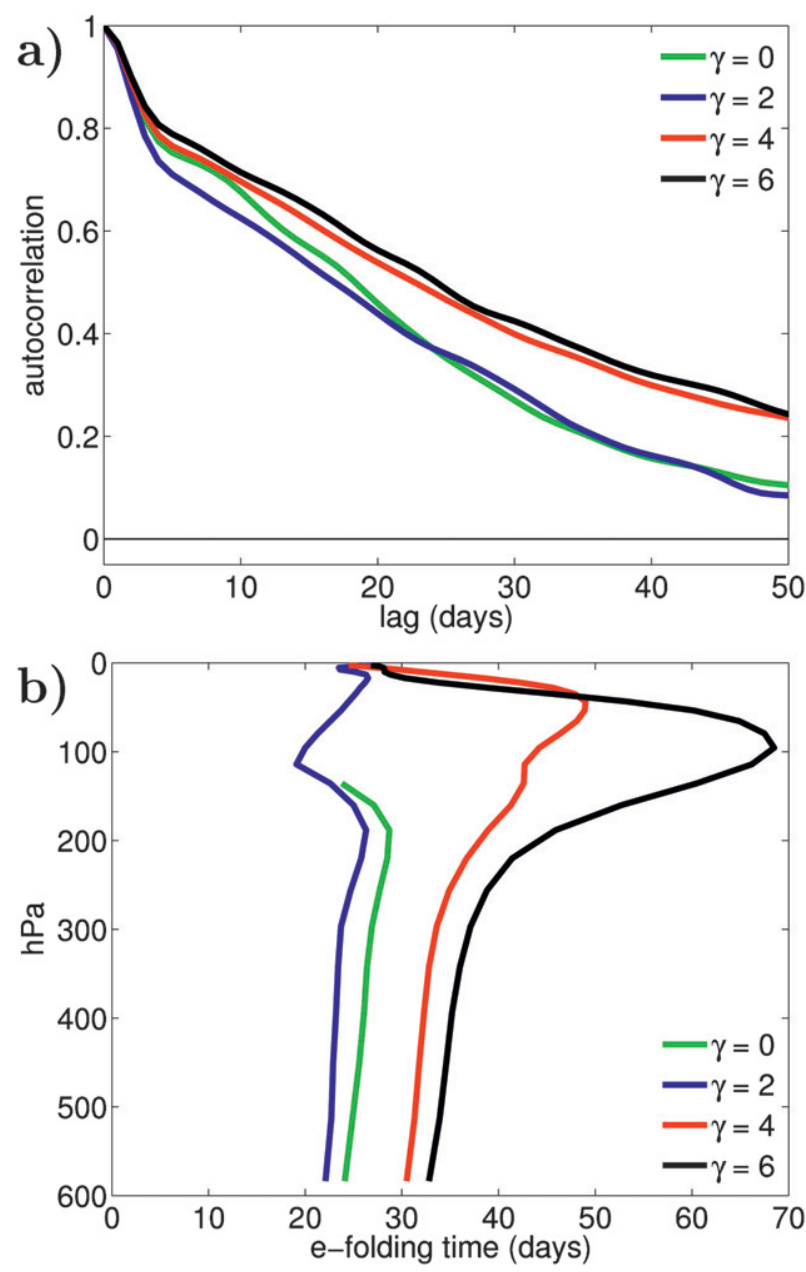

FIG. 9. Influence of stratospheric variability on the tropospheric variability: (a) The autocorrelation function of the tropospheric annular mode index at $513 \mathrm{hPa}$ for four integrations with varied polar vortex lapse rate $\gamma$. Forcing in the troposphere is identical in each case, with topography of wavenumber $m=2$ and amplitude $h_{0}=3000 \mathrm{~m}$. (b) The annular mode $e$-folding time scale as a function of pressure for the same four integrations with varied stratospheric forcing. Computations based on pressure levels below the topography are omitted, as well as in the stratosphere of $\gamma=0 \mathrm{~K} \mathrm{~km}^{-1}$ simulation. There is no polar vortex in this simulation and thus the stratospheric NAM no longer has the same physical meaning.

In Fig. 9b, we plot the $e$-folding time scale $\tau$ of the annular mode autocorrelation function at each pressure level. The time scale $\tau$ is obtained by finding the best least squares fit of $\exp (-t / \tau)$ to the annular mode autocorrelation function. ${ }^{6}$ The time scale of the annular

\footnotetext{
${ }^{6}$ The time scale $\tau$ is fit to the autocorrelation function for all times $t$ for which the autocorrelation function is greater than $1 / e$, as in Gerber et al. (2008b). This focuses on the variability on intraseasonal time scales, and not the tail of the distribution.
}

mode is larger throughout the depth of the troposphere in the two integrations with an active stratosphere. In these integrations the time scale of variability increases in the stratosphere where planetary waves intermittently perturb the polar vortex far from equilibrium. These large deviations allow the slow thermal recovery time scale of the lower stratosphere to dominate the evolution of the stratospheric annular mode index and also enable coupling that reddens the time scale $\tau$ of the tropospheric annular mode.

The profiles of $\tau$ as a function of height in Fig. 9b can be compared to their observational counterparts, shown in Fig. 1 of Baldwin et al. (2003). The time scale of the observed annular modes in the Northern Hemisphere winter is relatively constant through the depth of the troposphere and then increases substantially in the lower and midstratosphere, as seen in our model with an active stratosphere $\left(\gamma=4\right.$ and $\left.6 \mathrm{~K} \mathrm{~km}^{-1}\right)$. This suggests that the increased time scales of the stratosphere relative to the troposphere may be related to the dynamics of stratospheric warming events. In observations, the time scales of the annular mode in the troposphere peaks during winter in the Northern Hemisphere-the period of active SSWs-and in November in the Southern Hemisphere- the time of the final warming of the Antarctic vortex.

\section{Conclusions}

We have constructed an idealized general circulation model with the key features of observed stratospheretroposphere coupling on intraseasonal time scales and have used it to probe the influence of topographically induced stationary planetary waves on the coupling between the stratosphere and troposphere. With the appropriate topographic forcing, the model produces realistic stratospheric sudden warmings with the correct frequency and captures both the upward and downward exchange of information observed by Polvani and Waugh (2004) and Baldwin and Dunkerton (2001), respectively. The model demonstrates how the mean state of the stratosphere affects the mean state of the troposphere and how the variability of the stratosphere affects the variability in the troposphere.

Our model is based on that developed by PK02, and the results in this paper confirm and extend the conclusions of the earlier study: a stronger polar vortex in the time mean leads to a poleward shift in the tropospheric jet. Here we have demonstrated a more generic relationship between the strength of the stratospheric polar vortex and latitude of the tropospheric westerlies. Changes in the thermal forcing of the stratosphere or 
planetary wave forcing from the surface that favor a weaker polar vortex consistently favor an equatorward shift in tropospheric jet, as seen in Figs. 2 and 4. Detailed analysis uncovered a weakness in the earlier study, as the idealized model exhibits regime behavior in the absence of topography. This amplified the influence of the stratosphere in PK02. With topography, the results are now quantitatively similar to observations (Baldwin 2003). The robust relationship between the strength of the polar vortex and tropospheric jet suggests that proper representation of the stratospheric mean state is important in comprehensive climate models. Indeed, recent studies by Perlwitz et al. (2008) and Son et al. (2008) indicate that the trend of the Southern Hemisphere westerly jets is very sensitive to ozone forcing, and hence the temperature of the lower and middle stratosphere, in Intergovernmental Panel on Climate Change (IPCC) Fourth Assessment Report (AR4) and Chemistry-Climate Model Validation Activity (CCMVal) model simulations.

We also explored the connection between the strength of the stratospheric polar vortex and the latitude of the tropospheric jet on intraseasonal time scales, as characterized by the annular mode patterns of variability (Thompson and Wallace 2000; Baldwin et al. 2003). This coupling is reflected in the structure of annular modes in the model, which are confined to the troposphere in integrations with insufficient stationary wave forcing but penetrate deep into the stratosphere in the model with an active stratosphere, as shown in Fig. 7. Stratospheric sudden warmings produce large deviations from equilibrium, allowing the slow thermal recovery time scale of the stratosphere to play a large role in the variability. Comparison of integrations with identical forcing in the troposphere, but coupled to a passive or an active stratosphere, demonstrates that interactions with the stratosphere can increase the time scale of the tropospheric annular modes, as seen in Fig. 9. This suggests that an adequate representation of stratospheric variability may also be important in comprehensive climate models, which generally do not include a well-resolved stratosphere and thus do not produce realistic stratospheric variability. IPCC AR4 models in general do not capture the details of the seasonal cycle in tropospheric annular mode time scales, particularly in the Northern Hemisphere winter (Gerber et al. 2008a), and the response of a model's annular mode to climate perturbations may be sensitive to the time scales of its internal variability, as suggested by the fluctuationdissipation relationship (Leith 1975; Ring and Plumb 2008; Gerber et al. 2008b).

Kushner and Polvani (2004) and Song and Robinson (2004) argue that tropospheric eddies are essential in understanding the shift of the tropospheric jet induced by stratospheric perturbations. Thompson et al. (2006) find, rather, that the observed response of the troposphere to stratospheric perturbations may still be explained by arguments based on the zonally symmetric dynamical response. The former scenario is consonant with the findings of our model, as evidenced by the lag between the troposphere and the stratosphere following a sudden warming event. The lag occurs on the time scale of the model's annular mode, which is to first order set by eddy-mean flow interactions in the troposphere. Wittman et al. (2007) and Chen and Zurita-Gotor (2008) find evidence that the shear near the tropopause influences eddy wave breaking and, therefore, the tropospheric momentum budget, providing a possible pathway for the influence of the stratosphere. Our model behaves accordingly; in particular, the troposphere lingers on the slow recovery time scales of the lower stratosphere-and not that of the overall vortex. The sensitivity of the troposphere to the structure of the topographic forcing suggests that planetary scale waves may also play a critical role.

In conclusion, we stress the transparency provided by studying a model with idealized forcings. The realism of the coupling in this simple model suggests that accurate simulation of stratosphere-troposphere coupling may require only the correct representation of the largescale dynamics. It is likely that other physical processes (i.e., radiation, convection, gravity waves) influence the details of these phenomena, but they may not be essential for the coupling. The simple topography allows one to tune the stationary planetary wave forcing from the troposphere to the stratosphere. Once the wave flux is sufficient to produce stratospheric sudden warmings, coupling on intraseasonal time scales falls into place on its own. This suggests that intraseasonal stratospheretroposphere coupling in more sophisticated models may depend, largely, on their ability to simulate-or at least represent-stratospheric sudden warming events. Models with limited variability in the Arctic stratosphere are likely missing the full coupling. As evidenced in this study, this may bias both the climatology and variability of the model's troposphere.

Acknowledgments. We would like to express our gratitude to three anonymous reviewers for insightful comments on an earlier version of the manuscript, Darryn W. Waugh and Seok-Woo Son for helpful discussions, and to the scientists and staff of the Geophysical Fluid Dynamics Laboratory, where the integrations were performed. This work was supported in part by a grant from the National Science Foundation to Columbia University. 


\section{REFERENCES}

Baldwin, M. P., 2003: Comment on "Tropospheric response to stratospheric perturbations in a relatively simple general circulation model" by Lorenzo M. Polvani and Paul J. Kushner. Geophys. Res. Lett., 30, 1812, doi:10.1029/2003GL017793.

_ , and T. J. Dunkerton, 2001: Stratospheric harbingers of anomalous weather regimes. Science, 294, 581-584.

—, D. B. Stephenson, D. W. J. Thompson, T. J. Dunkerton, A. J. Charlton, and A. O'Neill, 2003: Stratospheric memory and skill of extended-range weather forecasts. Science, 301, 636-640.

Chan, C. J., and R. A. Plumb, 2009: The response to stratospheric forcing and its dependence on the state of the troposphere. $J$. Atmos. Sci., in press.

Charlton, A. J., and L. M. Polvani, 2007: A new look at stratospheric sudden warmings. Part I: Climatology and modeling benchmarks. J. Climate, 20, 449-469.

Charney, J. G., and P. G. Drazin, 1961: Propagation of planetaryscale disturbances from the lower into the upper atmosphere. J. Geophys. Res., 66, 83-109.

Chen, G., and P. Zurita-Gotor, 2008: The tropospheric jet response to prescribed zonal forcing in an idealized atmospheric model. J. Atmos. Sci., 65, 2254-2271.

Gerber, E. P., and G. K. Vallis, 2007: Eddy-zonal flow interactions and the persistence of the zonal index. J. Atmos. Sci., 64, 3296-3311.

— L. M. Polvani, and D. Ancukiewicz, 2008a: Annular mode time scales in the Intergovernmental Panel on Climate Change Fourth Assessment Report models. Geophys. Res. Lett., 35, L22707, doi:10.1029/2008GL035712.

_, S. Voronin, and L. M. Polvani, 2008b: Testing the annular mode autocorrelation time scale in simple atmospheric general circulation models. Mon. Wea. Rev., 136, 1523-1536.

Held, I. M., and M. J. Suarez, 1994: A proposal for the intercomparison of the dynamical cores of atmospheric general circulation models. Bull. Amer. Meteor. Soc., 75, 1825-1830.

Kushner, P. J., and L. M. Polvani, 2004: Stratosphere-troposphere coupling in a relatively simple AGCM: The role of eddies. $J$. Climate, 17, 629-639.

— den warming in a simple GCM: A prototype for the Southern Hemisphere warming of 2002? J. Atmos. Sci., 62, 890-897.

Lee, S., 1997: Maintenance of multiple jets in a baroclinic flow. $J$. Atmos. Sci., 54, 1726-1738.

Leith, C. E., 1975: Climate response and fluctuation dissipation. $J$. Atmos. Sci., 32, 2022-2026.

Matthewman, N. J., J. G. Esler, A. J. Charlton-Perez, and L. M. Polvani, 2009: A new look at stratospheric sudden warmings. Part III: Polar vortex evolution and vertical structure. J. Climate, 22, 1566-1585.

Newman, P. A., E. R. Nash, and J. E. Rosenfield, 2001: What controls the temperature of the Arctic stratosphere during spring? J. Geophys. Res., 106, 19 999-20 010.

Norton, W. A., 2003: Sensitivity of Northern Hemisphere surface climate to simulation of the stratospheric polar vortex. Geophys. Res. Lett., 30, 1627, doi:10.1029/2003GL016958.
Perlwitz, J., S. Pawson, R. L. Fogt, J. E. Nielsen, and W. D. Neff, 2008: Impact of stratospheric ozone hole recovery on Antarctic climate. Geophys. Res. Lett., 35, L08714, doi:10.1029/ 2008GL033317.

Plumb, R. A., and K. Semeniuk, 2003: Downward migration of extratropical zonal wind anomalies. J. Geophys. Res., 108, 4223, doi:10.1029/2002JD002773.

Polvani, L. M., and P. J. Kushner, 2002: Tropospheric response to stratospheric perturbations in a relatively simple general circulation model. Geophys. Res. Lett., 29, 1114, doi:10.1029/ 2001 GL014284.

— , and D. W. Waugh, 2004: Upward wave activity flux as a precursor to extreme stratospheric events and subsequent anomalous surface weather regimes. J. Climate, 17, 3548-3554.

Reichler, T., P. J. Kushner, and L. M. Polvani, 2005: The coupled stratopshere-troposphere response to impulsive forcing from the troposphere. J. Atmos. Sci., 62, 3337-3352.

Ring, M. J., and R. A. Plumb, 2008: The response of a simplified GCM to axisymmetric forcings: Applicability of the fluctuation-dissipation theorem. J. Atmos. Sci., 65, 3880-3898.

Scinocca, J. F., and P. H. Haynes, 1998: Dynamical forcing of stratospheric planetary waves by tropospheric baroclinic eddies. J. Atmos. Sci., 55, 2361-2392.

Scott, R. K., D. G. Dritschel, L. M. Polvani, and D. W. Waugh, 2004: Enhancement of Rossby wave breaking by steep potential vorticity gradients in the winter stratosphere. J. Atmos. Sci., 61, 904-918.

Son, S.-W., and Coauthors, 2008: The impact of stratospheric ozone recovery on the Southern Hemisphere westerly jet. Science, 320, 1486-1489, doi:10.1126/science.1155939.

Song, Y., and W. A. Robinson, 2004: Dynamical mechanisms for stratospheric influences on the troposphere. J. Atmos. Sci., 61, 1711-1725.

Taguchi, M., and S. Yoden, 2002: Internal interannual variability of the troposphere-stratosphere coupled system in a simple general circulation model. Part I: Parameter sweep experiment. J. Atmos. Sci., 59, 3021-3036.

- T. Yamaga, and S. Yoden, 2001: Internal variability of the troposphere-stratosphere coupled system simulated in a simple global circulation model. J. Atmos. Sci., 58, 31843203.

Thompson, D. W. J., and J. M. Wallace, 2000: Annular modes in the extratropical circulation. Part I: Month-to-month variability. J. Climate, 13, 1000-1016.

_ J. C. Furtado, and T. G. Shepherd, 2006: On the tropospheric response to anomalous stratospheric wave drag and radiative heating. J. Atmos. Sci., 63, 2616-2629.

U.S. Committee on the Extension to the Standard Atmosphere, 1976: U.S. Standard Atmosphere, 1976. U.S. Government Printing Office, $227 \mathrm{pp}$.

Williams, G. P., 2006: Circulation sensitivity to tropopause height. J. Atmos. Sci., 63, 1954-1961.

Wittman, M. A. H., A. J. Charlton, and L. M. Polvani, 2007: The effect of lower stratospheric shear on baroclinic instability. $J$. Atmos. Sci., 64, 479-496. 